\title{
Mild thyroid peroxidase deficiency caused by TPO mutations with residual activity: Correlation between clinical phenotypes and enzymatic activity
}

\author{
Satoshi Narumi ${ }^{1)}$, Larry A Fox ${ }^{2)}$, Keisuke Fukudome ${ }^{3), 4)}$, Zenichi Sakaguchi ${ }^{3)}$, Chiho Sugisawa ${ }^{5)}$, \\ Kiyomi $\mathrm{Abe}^{5)}$, Kaori Kameyama ${ }^{6)}$ and Tomonobu Hasegawa ${ }^{5)}$ \\ 1) Department of Molecular Endocrinology, National Research Institute for Child Health and Development, Tokyo 157-8535, Japan \\ 2) Division of Endocrinology, Nemours Children's Specialty Care, Jacksonville, FL 32207, USA \\ 3) Department of Pediatrics, Takamatsu Red Cross Hospital, Takamatsu 760-0017, Japan \\ 4) Department of Pediatric Cardiology, Shikoku Medical Center for Children and Adults, Zentsuji 765-8507, Japan \\ 5) Department of Pediatrics, Keio University School of Medicine, Tokyo 160-8582, Japan \\ 6) Department of Diagnostic Pathology, Keio University School of Medicine, Tokyo 160-8582, Japan
}

\begin{abstract}
Thyroid peroxidase (TPO) deficiency, caused by biallelic TPO mutations, is a well-established genetic form of congenital hypothyroidism $(\mathrm{CH})$. More than 100 patients have been published, and the patients have been diagnosed mostly in the frame of newborn screening (NBS) programs. Correlation between clinical phenotypes and TPO activity remains unclear. Here, we report clinical and molecular findings of two unrelated TPO mutation-carrying mildly hypothyroid patients. The two patients were born at term after an uneventful pregnancy and delivery, and were NBS negative. They sought medical attention due to goiter at age 8 years. Evaluation of the thyroid showed mild elevation of serum TSH levels, normal or slightly low serum T4 levels, high serum T3 to T4 molar ratio, high serum thyroglobulin levels, and high thyroidal ${ }^{123} \mathrm{I}$ uptake. We performed next-generation sequencing-based genetic screening, and found that one patient was compound heterozygous for two novel TPO mutations (p.Asp224del; c.820-2A>G), and the other was homozygous for a previously known mutation (p.Trp527Cys). In vitro functional analyses using HEK293 cells showed that the two amino acid-altering mutations (p.Asp224del and p.Trp527Cys) caused partial loss of the enzymatic activity. In conclusion, we report that TPO mutations with residual activity are associated with mild TPO deficiency, which is clinically characterized by marked goiter, mild TSH elevation, high serum T3 to T4 molar ratio, and high serum thyroglobulin levels. Our findings illuminate the hitherto under-recognized correlation between clinical phenotypes and residual enzymatic activity among patients with TPO deficiency.
\end{abstract}

Key words: Congenital hypothyroidism, Newborn screening, Thyroid peroxidase (TPO), Mutation, Genetics

CONGENITAL HYPOTHYROIDISM (CH) is the most common congenital endocrine disorder affecting about 1 in 2,000-4,000 newborns [1]. CH is recognized as one of the most common causes of preventable intellectual disability. In virtually all developed countries, newborn screening (NBS) programs were implemented to enable early diagnosis and treatment, hereby preventing intellectual disability. As a result, the vast

Submitted May 4, 2017; Accepted Jul. 24, 2017 as EJ17-0194 Released online in J-STAGE as advance publication Sep. 1, 2017 Correspondence to: Satoshi Narumi, M.D., Ph.D., Department of Molecular Endocrinology, National Research Institute for Child Health and Development, 2-10-1 Okura, Setagaya-ku, Tokyo 157-8535, Japan.

E-mail: narumi-s@ncchd.go.jp

(C) The Japan Endocrine Society majority of $\mathrm{CH}$ patients, including mild ones, are diagnosed in the frame of NBS in those countries.

Thyroid peroxidase (TPO) is a thyroid-specific membrane-bound enzyme that plays a crucial role in production of the thyroid hormones. TPO oxidizes iodide ions to form iodine atoms for addition onto tyrosine residues on thyroglobulin $(\mathrm{Tg})$ for the production of iodotyrosine residues (mono-iodinated tyrosine or di-iodinated tyrosine). TPO also catalyzes the coupling reaction of two iodotyrosine residues, ultimately forming $\mathrm{T}_{3}$ or $\mathrm{T}_{4}$ residues in $\mathrm{Tg}$. TPO deficiency is a well-established genetic form of $\mathrm{CH}$. In 1950, the disease was originally described by Stanbury and Hedge [2] as an autosomal-recessive form of $\mathrm{CH}$ characterized by inability to utilize iodine in the thyroid. 
Identification of the disease-causing mutations involving the TPO gene (TPO) was achieved by Abramowicz et al. in 1992 [3]. Since then, more than 100 molecularly-confirmed cases harboring more than 70 distinct mutations have been published worldwide [4]. Likely due to the presence of a common founder frameshift mutation, referred as "GGCC insertion in exon 8" in the literature [3], the TPO deficiency seems more frequently observed in Caucasians than in other ethnic groups. A genetic epidemiology study conducted in the Netherlands showed that the frequency of the deficiency was 1 in 66,000 among the general Dutch populations, accounting for roughly $3 \%$ of total $\mathrm{CH}$ cases [5]. The classical hallmark of the TPO deficiency is total iodine organification defect, in which more than $90 \%$ of accumulated intrathyroidal radioiodine is released after administration of perchlorate [5]. A minor subset of TPO mutation carriers have partial iodine organification defect, though the frequency of the phenotype remains unknown.

Whether iodine organification is total or partial, TPO deficiency is congenital, and the disease is lifelong (i.e., permanent $\mathrm{CH}$ ). Thus, it seems natural that hypothyroidism in TPO mutation carriers can readily be detected through the NBS programs. Here, we report two TPO mutation-carrying mildly hypothyroid patients that had negative NBS results. The two unrelated patients came to medical attention due to goiter, had a mildly elevated serum TSH level, and exhibited characteristic high serum $\mathrm{T}_{3}$ to $\mathrm{T}_{4}$ molar ratio. Functional analyses revealed that the mutant TPO proteins retained significant residual peroxidase activity, likely explaining the milder phenotypes than most previous cases.

\section{Materials and Methods}

\section{Patients}

Patient 1, the third child of healthy non-consanguineous Japanese parents, was a female born at term after an uneventful pregnancy and delivery. She received TSH-based NBS. The result, reported by the parents, was negative. She developed goiter at age 8 years. She had normal height $(126.0 \mathrm{~cm} ;-0.2 \mathrm{SD})$ and normal BMI (z-score, -0.6). No symptoms or signs suggesting hypothyroidism were noted. She had markedly large thyroid gland, which was soft to palpation. Blood test showed a slightly elevated serum TSH $(6.5 \mathrm{mU} / \mathrm{L}$, reference $0.5-5.0$ ), normal thyroid hormones (free $\mathrm{T}_{4} 0.99$ $\mathrm{ng} / \mathrm{dL}$, reference $0.90-1.80$; free $\mathrm{T}_{3} 4.1 \mathrm{pg} / \mathrm{mL}$, reference 2.6-4.9) with an elevated serum $\operatorname{Tg}(1,057 \mathrm{ng} / \mathrm{mL}$; reference $<30 \mathrm{ng} / \mathrm{mL}$ ) (Fig. 1). Serum levels of antiTPO antibody and anti-Tg antibody were normal. On
Patient 1

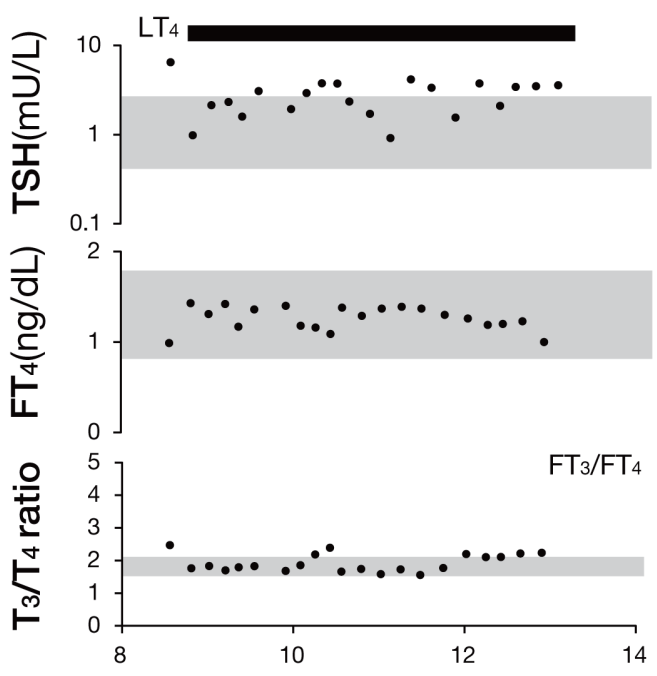

Patient 2
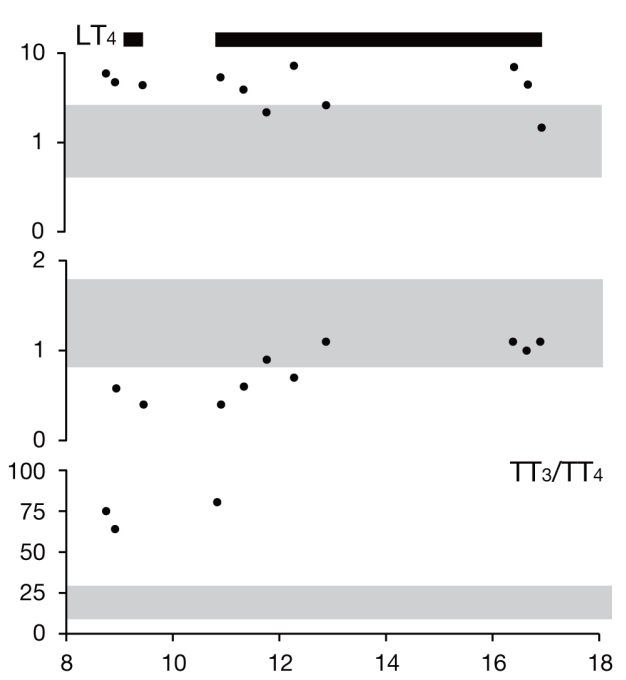

Fig. 1 Chronological changes of serum TSH level, serum free $T_{4}$ levels, and serum $T_{3}$ to $T_{4}$ molar ratio (free $T_{3} /$ free $T_{4}$ in Patient 1 , total $T_{3} /$ total $T_{4}$ in Patient 2) are shown. Shaded areas indicate reference ranges. The two patients had mildly elevated TSH levels and characteristic high $\mathrm{T}_{3} / \mathrm{T}_{4}$ molar ratio.

Abbreviations: $\mathrm{FT}_{3}$, free $\mathrm{T}_{3} ; \mathrm{FT}_{4}$, free $\mathrm{T}_{4} ; \mathrm{LT}_{4}$, levothyroxine replacement therapy, $\mathrm{TT}_{3}$, total $\mathrm{T}_{3} ; \mathrm{TT}_{4}$, total $\mathrm{T}_{4}$. 
ultrasonography, the thyroid gland was not only very large (estimated thyroid volume, $68 \mathrm{~mL}$ ) but also showed increased vasculature (Fig. 2A). She had high thyroidal ${ }^{123} \mathrm{I}$ uptake $(65 \%$ at $4 \mathrm{~h}$; reference $5-15 \%)$, and the perchlorate discharge rate was high $(35.4 \%$; reference $<10 \%$ ). She was treated with levothyroxine. $\mathrm{FT}_{3}$ to $\mathrm{FT}_{4}$ molar ratio was high at the diagnosis of subclinical hypothyroidism $(0.49$, in-house reference 0.33-0.41), normalized after starting therapy, but became constantly high after age 12 years (Fig. 1). Since the initiation of treatment, progression of goiter was stopped. There were no recognizable abnormalities in growth, intelligence and pubertal development.

Patient 2,an 8-year-old Caucasian boy born in USA, sought medical attention for goiter. He had mild speech delay but growth in height was normal. The result of NBS, reported by the parents, was negative. His family history was positive for maternal grandfather and maternal great uncle both having thyroid cancer (tissue types unknown). On physical examination, his enlarged thyroid gland was soft and asymmetric $(\mathrm{R}>\mathrm{L})$. Thyroid function test showed a slightly high serum TSH (5.9 mU/L)(Fig. 1), a low total T4 $(3.5 \mu \mathrm{g} /$ $\mathrm{dL}$; reference 6.0-13.8), and a high total $\mathrm{T}_{3}(2.20 \mathrm{ng} /$ $\mathrm{mL}$; reference $0.60-1.81$ ). He had slightly high serum $\mathrm{Tg}(250 \mathrm{ng} / \mathrm{mL})$. Serum levels of anti-TPO antibody and anti-Tg antibody titers were normal. ${ }^{123}$ I uptake was elevated $(72 \%$ at $4 \mathrm{~h})$. Perchlorate discharge test was not performed. His goiter was not improved by levothyroxine treatment, and actually worsened. $\mathrm{He}$
A

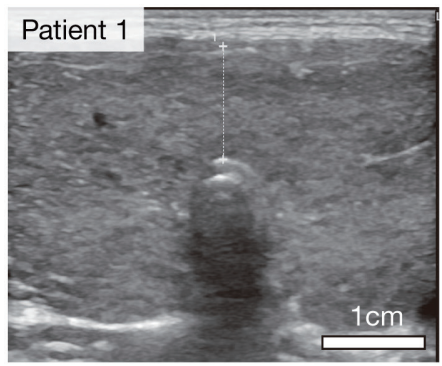

B

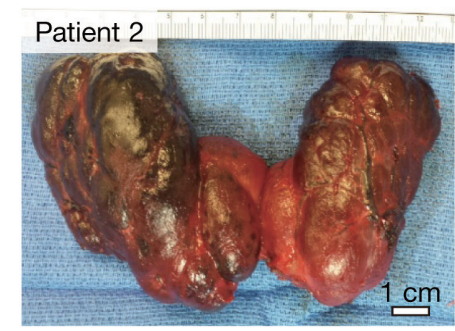

D

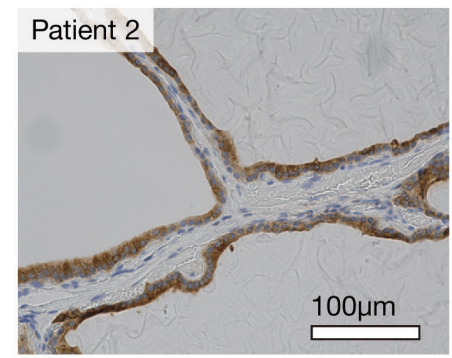

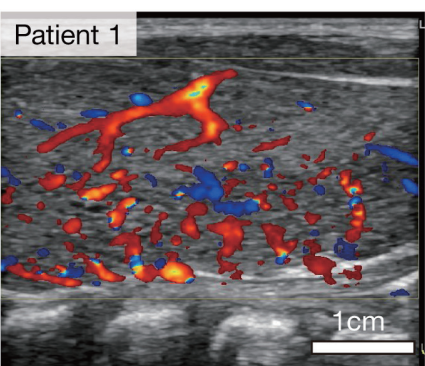

C
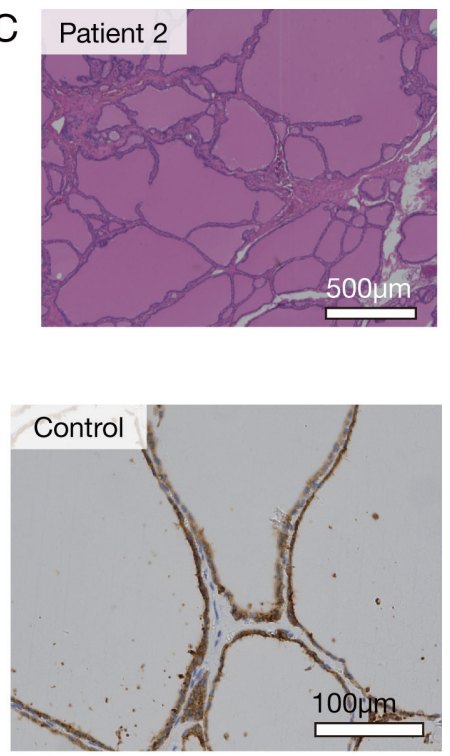

Fig. 2 Thyroid morphology and histology of Patient 1 and Patient 2

(A) Ultrasonography showed marked goiter in Patient 1 (left panel), with increased vascularity on color Doppler ultrasound (right panel). (B) Photographic image of resected thyroid gland of Patient 2. (C) Histological analysis of the resected thyroid specimen showed irregular and distended macrofollicles. (D) Immunohistochemical staining of TPO showed no significant difference between Patient 2 (left panel) and a control (right panel). 
received thyroidectomy at age 17 years (the weight of the resected gland was 102 g, Fig. 2B). Histological analysis showed irregular and distended macrofollicles with scattered delicate papillary infoldings, dense colloid, and absence of resorption vacuoles (Fig. 2C). Immunohistochemical stain showed expression of the TPO protein in the thyroid follicular cells that was comparable to a control (Fig. 2D). Simultaneous measurements of $\mathrm{T}_{3}$ and $\mathrm{T}_{4}$ were conducted three times, when the patient was not treated, and very high serum total $\mathrm{T}_{3}$ to total $\mathrm{T}_{4}$ molar ratio $(0.075,0.064$ and 0.080 ; reference $0.010-0.027)[6]$ was observed.

\section{Mutation detection}

This study was approved by the Ethics Committee of Keio University School of Medicine. Written informed consent for the molecular study was obtained from the parents or legal guardians of the probands. Genomic DNA samples were collected from the probands and family members if available. Ten known genes associated with $\mathrm{CH}$ (DUOX2, DUOXA2, IYD, NKX2-1, PAX8, SLC5A5, SLC26A4, TG, TPO and $T S H R$ ) were analyzed with use of a next generation sequencer MiSeq (Illumina Inc., San Diego, CA, USA) according to the SureSelect protocol (Agilent Technologies, Santa Clara, CA, USA) as described previously [7]. Base calling, read filtering, and demultiplexing were performed with the standard Illumina processing pipeline. We used BWA 0.7.5 for alignment against the human reference genome (NCBI build 37; hg19) with the default settings. Local realignment, quality score recalibration and variant calling were performed by GATK 3.2.0 [8] with the default settings. We used ANNOVAR [9] for annotation of called variants. The detected mutation was confirmed by standard PCR-based Sanger sequencing with previously described methods [10]. We referred the frequencies of the mutations in the variant databases, including 1,000 Genomes Project (1KG; http://www.internationalgenome.org/), Exome Aggregation Consortium (ExAC; http://exac.broadinstitute.org/) and Human Genetic Variation Database (HGVD; http://www.genome.med. kyoto-u.ac.jp/SnpDB/). Descriptions of the mutations were based on NM_000547.5.

\section{Functional analyses}

A vector encoding C-terminal hemagglutinin-tagged human TPO (TPO-HA) was created by insertion of TPO cDNA sequence into pEGFP-N1 (Clonetech lab- oratories, Palo Alto, CA), and substitution of the EGFP sequence by the HA sequence with the Gibson assembly technique (NEBuilder HiFi DNA Assembly Master Mix; New England Biolabs, Ipswich, MA, USA). The two TPO mutations (p.Asp224del, and p.Trp527Cys) were introduced by site-directed mutagenesis (TaKaRa Bio Inc, Tokyo, Japan). Expression vectors for stable expression of (untagged) TPO [wildtype (WT), p.Asp224del, p.Trp527Cys and p.Arg341Gln] were created by insertion of TPO cDNA sequence into pB513B-1 (System Biosciences, Palo Alto, CA, USA) with the Gibson assembly technique.

HEK293 cells were maintained in DMEM supplemented with $50 \mathrm{U} / \mathrm{mL}$ penicillin, $50 \mu \mathrm{g} / \mathrm{mL}$ streptomycin and $10 \%$ fetal bovine serum. In a series of expression experiments, we assessed a previously reported TPO mutants (p.Arg341Gln [10]) as a representative of nonfunctional mutation. We also analyzed the p.Gly387Arg mutation that was observed in patients showing the mild TPO deficiency phenotype [11]. Stable HEK293 cell lines expressing each TPO protein (WT, p.Asp224del, p.Trp527Cys, p.Gly387Arg and p.Arg341Gln) were established using the piggyback system according to the manufacturer's protocol. For immunoblot analysis, stable cells were grown in a 6 -well plate to about $95 \%$ confluency, washed twice with PBS, and lysed with $200 \mu \mathrm{L}$ of $0.5 \%$ Triton-X100 in PBS. Cell lysates were subject to $10 \%$ SDSPAGE, and Western blot was performed with use of the anti-TPO rabbit monoclonal antibody ab109383; Abcam, Cambridge, MA, USA) as a primary antibody. For measurement of peroxidase activity, we established stable cell lines expressing each TPO protein (WT, p.Asp224del, p.Trp527Cys,p.Arg341Gln and p.Gly387Arg) according to the manufacturer's protocol. We prepared $90 \%$ confluent stable cells in 6-cm dishes, trypsinized and washed cells twice with PBS, and resuspended them in $200 \mathrm{uL}$ of $1 \times$ Earle's balanced salt solution (Sigma Aldrich, St. Louis, MO, USA) containing $100 \mu \mathrm{M}$ Amplex Red reagent (Thermo Fisher Scientific) and $2 \mathrm{mM} \mathrm{H} \mathrm{O}_{2}$. After 1-hour shaking incubation at room temperature, fluorescent emission was measured with the FlexStation 3 Microplate Reader (Molecular Devices, Sunnyvale, CA, USA). The assay was performed to quantify the peroxidase activity of the stable HEK293 cells. When we perform the assay for WT-TPO expressing cells with permeabilizing plasma membrane, increase of the activity (about 15\%) was observed, indicating that 
the peroxidase activity was chiefly derived from the cell surface. The activity of each mutant is expressed as a percentage (mean \pm SEM) of WT activity. The background activity, which was measured with use of non-transfected cells, was set to $0 \%$. Data are representative of three independent experiments (each performed in triplicate) with similar results. Welch's $t$-test was used for comparisons of the activity.

\section{Results}

\section{Mutation detection}

The next generation sequencing-based genetic screen led us to identify biallelic mutations in both patients. Patient 1 was compound heterozygous for a novel 3-bp deletion causing a loss of one amino acid residue Asp224 (c.670_672del, p.Asp224del) (Fig. $3 \mathrm{~A})$. The Asp224 residue is conserved among mammalian species (Fig. 3B). She also had a novel splice site mutation, c.820-2A $>\mathrm{G}$, affecting the boundary of intron 6 and exon 7 (Fig. 3A). The c.820-2A>G mutation was derived from the father, while the p.Asp224del mutation was derived from the mother (Fig. 3C). The elder sister of the proband had the p.Asp224del mutation in the heterozygous state. Patient 2 was homozygous for a previously reported missense mutation (Fig. 3A), p.Trp527Cys [5], affecting the evolutionarily conserved amino acid residue (Fig. 3B). Parental genotyping was unavailable.

The c. $820-2 \mathrm{~A}>\mathrm{G}$ splice site mutation was not

A

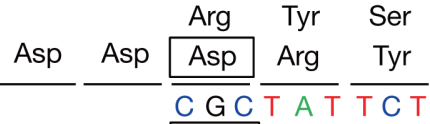

G A T GA T GACC GC TA T

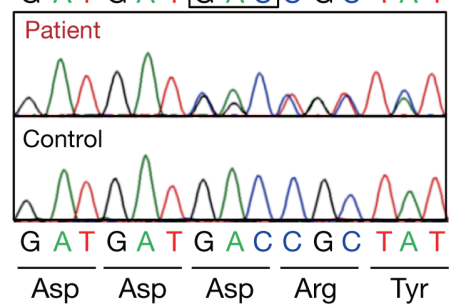

B

\begin{tabular}{rc} 
& p.Asp224del \\
Mutation & VTDD-RYSD \\
\hline Human & VTDDDRYSD \\
Mouse & VTEDDQYSD \\
Rat & VTEDDQYSD \\
Chicken & VTEDNLYSD \\
Xenopus & FREDDLYSH \\
Zebrafish & LQEDRDYSQ
\end{tabular}

p.Trp527Cys

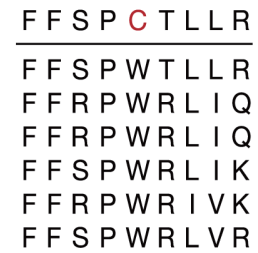

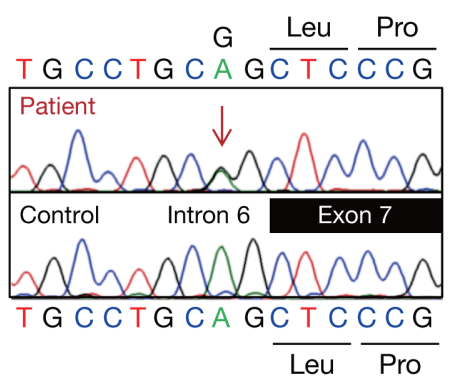

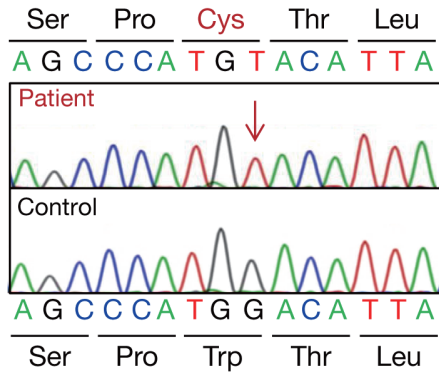

C

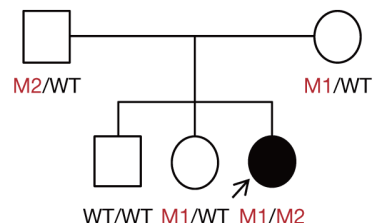

$\mathrm{TSH}(\mathrm{mU} / \mathrm{L}) \quad 1.7 \quad 1.3 \quad 6.5$

$\begin{array}{llll}\mathrm{FT}_{4}(\mathrm{ng} / \mathrm{dL}) & 1.15 & 1.13 & 0.92\end{array}$

$\begin{array}{llll}\mathrm{FT}_{3}(\mathrm{pg} / \mathrm{mL}) & 3.8 & 3.7 & 4.1\end{array}$

$\operatorname{Tg}(\mathrm{ng} / \mathrm{mL}) \quad 21 \quad 25 \quad 1,057$

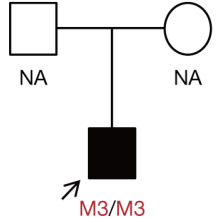

5.9

0.58

NA

NA

M1 p.Asp244del M2 c.820-2A>G M3 p.Trp527Cys WT Wildtype

Fig. 3 Identification of TPO mutations

(A) Partial electropherograms of the three identified TPO mutations. Patient 1 was compound heterozygous for a novel one amino-acid deletion (p.Asp224del, the deleted nucleotides are indicated in a box) and a novel splice site mutation (c.820-2A $>\mathrm{G}$, red arrow). Patient 2 had a previously known missense mutation (p.Trp527Cys, red arrow) in a homozygous state. (B) The residues affected by the amino acid-altering mutations ( Asp $^{224}$ and $\operatorname{Trp}^{527}$ ) were conserved across the mammalian species (i.e., human, mouse and rat). (C) Pedigrees of the Patient 1 (left) and Patient 2 (right). The two patients were sporadic. Values presented below each symbol indicate thyroid function test results. Squares, men; circles, women; solid symbols, affected by hypothyroidism; open symbols, unaffected. Abbreviations: FT3, free T3; FT4, free T4;NA, not available; Tg, thyroglobulin; WT, wildtype. 
registered in $1 \mathrm{KG}$, ExAC or HGVD. The p.Asp224del and the p.Trp527Cys mutations were registered in the ExAC database with extremely low allele frequency (0.000057 and 0.00010 , respectively).

\section{Functional analyses}

To confirm the pathogenicity of previously uncharacterized amino acid-altering mutations (p.Asp224del and p.Trp527Cys), we conducted in vitro expression experiments. The protein expression levels of the mutants, which were evaluated by transient transfection and Western blotting, were comparable to that of WT protein (Fig. 4A). The in vitro observation of the p.Trp527Cys mutation was consistent with the in vivo observation in Patient 2, which showed normal TPO immunostaining (Fig. 2D). We generated HEK293 cell lines that stably express each TPO protein (WT or mutant), and cell surface peroxidase activity were measured with use of Amplex Red reaction. We found that the p.Asp224del mutant and the p.Trp527Cys mutant had partial peroxidase activity, which were $56 \pm 6 \%(p=0.012)$ and $31 \pm 3 \%(p<0.001)$ of WT, respectively (Fig. 4B). In this assay, a previously reported nonfunctional mutation p.Arg341Gln [10] showed negligible activity (Fig. 4B). We also analyzed a previously reported but uncharacterized mutation p.Gly387Arg, which had been observed in $\mathrm{CH}$ patients with negative NBS results, and confirmed that the mutant also retained residual activity (Fig. 4B).

\section{Discussion}

In this report, we described two TPO mutation carriers that had negative NBS results, marked goiter, mildly elevated serum TSH levels high serum $\mathrm{T}_{3}$ to $\mathrm{T}_{4}$ molar ratio, and elevated serum Tg. Expression experiments revealed that the two amino-acid altering mutations (p.Asp224del and p.Trp527Cys) were loss-offunction mutations, but retained significant residual enzymatic activity. We presume that the two patients had mild TPO deficiency.

After the implementation of NBS programs, the vast majority of TPO mutation carriers have been diagnosed via NBS. To our knowledge, only five mutation-carrying patients (belonging to two families) that were missed by NBS have been reported. Kotani et al. described three siblings with compound heterozygous TPO mutations (p.[Gly553Cys];[Asp574_Leu575del]) [12]. Presenting symptom of the first and second children was goiter at ages 12 and 8 years, respectively. The third child had no symptoms, but received ultrasonography at age 8 months due to the family history, and goiter was shown. Lee et al. described three siblings with a homozygous TPO mutation (p.Gly387Arg)[11].
A

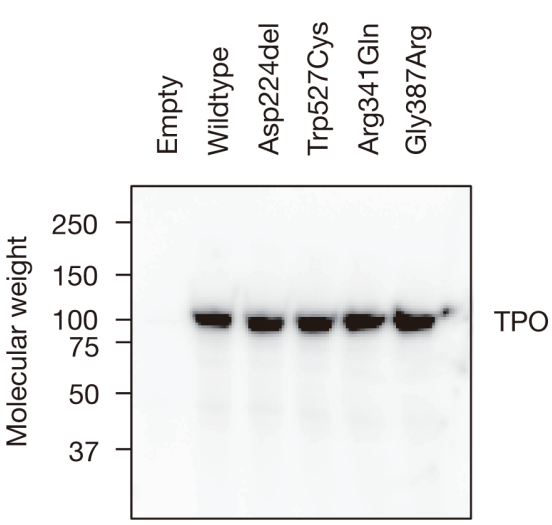

B

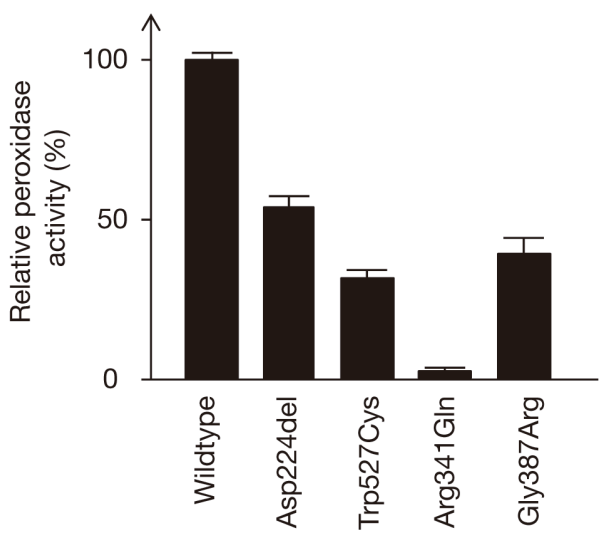

Fig. 4 Functional characterization of the identified amino acid-altering TPO mutations (p.Asp224del and p.Trp527Cys)

The p.Arg341Gln mutation was analyzed as a representative of nonfunctional mutations. The p.Gly387Arg mutation, which had been observed in patients with the mild TPO deficiency phenotype was also analyzed. (A) Western blotting showed no significant changes in protein expression levels between the mutants and wildtype. The image is a representative of three independent experiments with similar results. (B) Peroxidase activity of the p.Asp224del mutant and the p.Trp527Cys mutant were significantly lower than the wildtype ( $56 \pm 6 \%$ and $31 \pm 3 \%$, respectively), though residual activity were observed. The p.Arg341Gln mutant was nonfunctional. The p.Gly387Arg mutation retained residual activity. Data are representative of three independent experiments, each performed in triplicate, with similar results. Bars indicate standard error of the mean. 
Among the three affected siblings, the proband (fourth child) was diagnosed as having $\mathrm{CH}$ in the frame of NBS, while the remaining two (first and third children) had negative NBS results and developed goiter at ages 19 and 12 years, respectively. The five NBSnegative patients in the literature and our two patients had very mild elevation of serum TSH levels (3.8-9.2) (Table 1), and thus the levels did not seem to reach the screen cutoff. An alternative explanation for the negative NBS is delayed elevation of serum TSH in these patients. However, considering that the proband of the family with the homozygous p.Gly387Arg mutation had a positive NBS result, it is more likely that TSH was also elevated in the NBS-negative patients in their newborn periods, but the degrees were mild. However, this cannot be proven in the absence of thyroid function test data in the newborn period.

False negative NBS results are not specific to the mild TPO deficiency but also occur in patients with mild $\mathrm{CH}$. The characteristic finding was high serum $\mathrm{T}_{3}$ to $T_{4}$ molar ratio, observed not only in our two patients but also in three siblings reported by Kotani et al. (FT3 to FT4 molar ratio: $0.47,0.47$ and 0.67) (Table 1). The $\mathrm{T}_{3}$ to $\mathrm{T}_{4}$ molar ratio values in Patient 1 correlated well with serum TSH levels $\left(\mathrm{R}^{2}=0.48, p=0.0028\right)$ and high $\mathrm{T}_{3}$ to $\mathrm{T}_{4}$ molar ratio was observed when serum TSH levels were also high. This TSH-dependent elevation of $T_{3}$ to $T_{4}$ molar ratio indicates that increased $T_{3}$ is derived from the thyroid (but not converted from $\mathrm{T}_{4}$ in peripheral tissues), because secretion of $\mathrm{T}_{3}$ from the thyroid varies depending on serum TSH levels [13]. Similar high $\mathrm{T}_{3}$ to $\mathrm{T}_{4}$ molar ratio phenotype has also been described in patients with adult-onset $\mathrm{Tg}$ deficiency [14-16]. In patients with $\mathrm{Tg}$ deficiency, increased thyroidal type 2 iodothyronine deiodinase activity was shown by measurements of the enzymatic activity of frozen thyroid resection samples. The upregulation of type 2 iodothyronine deiodinase suggests that the mutation-carrying thyroid glands secrete T3 more preferentially than usual, possibly an adaptation to the $\mathrm{Tg}$ deficiency. We presume similar adaptive response might occur in patients with mild TPO deficiency, but a lack of frozen samples prevents us from performing verification studies.

Although more than 70 TPO mutations have been reported, in vitro determination of enzymatic activity has been performed only for 12 mutations (Supplementary Table 1)[10, 12, 17-19]. Ten out of the 12 mutations had no measurable activity, while two (p.Asp574_Leu575del and p.Gly590Ser) had residual activity $[12,17]$. The p.Gly590Ser mutation had nearnormal enzymatic activity, although it was observed in a patient with total iodine organification defect [17]. The discrepancy between experimental and clinical

Table 1 Phenotypes of mild TPO deficiency

\begin{tabular}{|c|c|c|c|c|c|c|c|c|}
\hline Variables & $\begin{array}{l}\text { Family } \\
\text { A-1[12] }\end{array}$ & $\begin{array}{l}\text { Family } \\
\text { A-2 [12] }\end{array}$ & $\begin{array}{l}\text { Family } \\
\text { A-3 [12] }\end{array}$ & $\begin{array}{l}\text { Family } \\
\text { B-1 [11] }\end{array}$ & $\begin{array}{l}\text { Family } \\
\text { B-2 [11] }\end{array}$ & $\begin{array}{l}\text { Family } \\
\mathrm{C}-1^{\mathrm{a}}\end{array}$ & $\begin{array}{l}\text { Family } \\
\mathrm{D}-1^{\mathrm{a}}\end{array}$ & Reference \\
\hline TPO genotype & $\begin{array}{c}\text { p.G553C } \\
\text { p.D574 } \\
\text { L_575del }\end{array}$ & $\begin{array}{l}\text { p.G553C } \\
\text { p.D574 } \\
\text { L5575del }\end{array}$ & $\begin{array}{l}\text { p.G553C } \\
\text { p.D574 } \\
\text { L5575del }\end{array}$ & $\begin{array}{c}\text { p.G387R } \\
\text { (homozygous) }\end{array}$ & $\begin{array}{c}\text { p.G387R } \\
\text { (homozygous) }\end{array}$ & $\begin{array}{l}\text { p.D224del } \\
\text { c.820-2A>G }\end{array}$ & $\begin{array}{c}\text { p.W527C } \\
\text { (homozygous) }\end{array}$ & \\
\hline Sex & M & M & $\mathrm{F}$ & $\mathrm{F}$ & $\mathrm{F}$ & $\mathrm{F}$ & M & \\
\hline Age at diagnosis (year) & 12 & 8 & $0^{\mathrm{b}}$ & 19 & 12 & 8 & 8 & \\
\hline Presenting symptom & Goiter & Goiter & Goiter $^{\mathrm{b}}$ & Goiter & Goiter & Goiter & Goiter & \\
\hline Serum TSH (mU/L) & 4.0 & 6.0 & 9.2 & $5.4^{\mathrm{c}}$ & $3.8^{\mathrm{c}}$ & 6.5 & 5.9 & $0.5-5.0$ \\
\hline Serum free $\mathrm{T}_{4}(\mathrm{ng} / \mathrm{dL})$ & 0.9 & 0.7 & 1.3 & $1.2^{\mathrm{c}}$ & $0.9^{\mathrm{c}}$ & 1.0 & NA & $0.9-1.8$ \\
\hline Serum free $T_{3}(\mathrm{pg} / \mathrm{mL})$ & 3.7 & 4.0 & 5.3 & NA & NA & 4.1 & NA & $2.6-4.9$ \\
\hline Free $T_{3} /$ free $T_{4}$ molar ratio & 0.47 & 0.67 & 0.47 & NA & NA & 0.48 & NA & $0.33-0.41$ \\
\hline Serum Tg $(\mathrm{ng} / \mathrm{mL})$ & 123 & 129 & 577 & NA & 999 & 1,057 & 250 & $<30$ \\
\hline${ }^{123}$ I uptake $(\%, \mathrm{~h})$ & 35,3 & 35,3 & NA & NA & NA & 65,4 & 72,4 & $5-15^{\mathrm{d}}$ \\
\hline $\mathrm{KClO} 4$ discharge rate $(\%)$ & 84 & 76 & NA & NA & NA & 35 & NA & $<10$ \\
\hline
\end{tabular}

${ }^{a}$ Present report. ${ }^{b}$ The patient had no symptoms, but received ultrasonography at age 8 months due to the familial history, and goiter was shown. ${ }^{\mathrm{c}}$ Data obtained through personal communication from Dr Muhammad Yazid Jalaludin (Department of Paediatrics, Faculty of Medicine, University of Malaya, Malaysia). ${ }^{\mathrm{d}}$ Reference range for ${ }^{123}$ I uptake at $4 \mathrm{~h}$. 
data could be due to the location of the p.Gly590Ser mutation (the last nucleotide of exon 10; reference sequence: NM_000547), because the mutation could prevent normal splicing and result in truncation of the gene product. The p.Asp574_Leu575del mutation retains about $50 \%$ enzymatic activity as compared with WT, and was observed in three NBS-negative siblings (i.e., mild TPO deficiency)[12]. In the present study, we showed that the two amino-acid altering mutations (p.Asp224del and p.Trp527Cys) retains significant residual activity, and were associated with a mild phenotype. The p.Asp224del mutation has about 50\% activity as compared with WT. Considering that the other TPO allele was seemingly a nonfunctional splice site mutation (c.820-2A>G), the total TPO activity of Patient 1 is approximately $25 \%$, on assumption that both alleles are expressed at the same level. The peroxidase activity of the other mutation, p.Trp527Cys, was about $30 \%$ as compared with WT. Patient 2 was homozygous for the p.Trp527Cys mutation, and thus the total TPO activity is expected to be approximately $30 \%$. Of interest, heterozygous p.Trp527Cys mutation, along with heterozygous p.Gln446His mutation, has been observed in three siblings with severe permanent $\mathrm{CH}$ [20], indicating that the p.Trp527Cys mutation can produce both mild and severe phenotype, depending on the activity of the opposite allele.

The two patients described in the present report had very large goiter, although their serum TSH levels were only modestly elevated. Obviously, size of thyroid gland in untreated thyroid dyshormonogenesis varies depending on not only serum TSH levels but also duration of hyperthyrotropinemia. Thus, the long untreated duration (8 years) may explain the development of very large goiter. Moreover, we presume that direct effect(s) of the mutant TPO proteins contributed goiter development. The size of thyroid gland of the two patients was not completely reversed after initiation of levothyroxine treatment, implying direct and TSHindependent effect(s) of the mutant proteins. Through analyses of thyroid tissues derived from $\mathrm{Tg}$-deficient patients, Baryshev et al. proposed that unfolded protein response triggered by mutant $\mathrm{Tg}$ proteins play a role in goiter development [21]. Similar mechanisms could be valid for TPO mutations.

Environmental factors, such as iodine intake level, are known to modify the clinical pictures of both genetic and non-genetic hypothyroidism. In some forms of thyroid dyshormonogenesis, including sodium-iodine symporter defect [22] and dual oxidase 2 defect [23], excessive amount of iodine seems to rescue the thyroid hormone-producing capacity. The two TPO mutation-carrying patients described in the present study lived in iodine-sufficient countries (Japan and USA), possibly let the clinical phenotype relatively mild.

Collectively, we suggest a previously under-recognized correlation between residual enzymatic activity and clinical phenotypes. It has long been known that biallelic nonfunctional TPO mutations (total TPO activity ranging from 0 to about $15 \%$ ) produce iodine organification defect, while monoallelic (i.e., heterozygous) mutation carriers (total TPO activity, 50\%) have normal thyroid function (Supplementary Fig. 1). Here, we define a new subtype of TPO deficiency, mild TPO deficiency, caused by TPO mutations with residual activity (total TPO activity, about $30 \%$ ). The typical phenotypes of mild TPO deficiency includes marked goiter, mildly elevated increased TSH levels, high serum $\mathrm{T}_{3}$ to $\mathrm{T}_{4}$ molar ratio, and elevated serum Tg levels.

\section{Acknowledgments}

The authors thank Ms. Saori Miyasako for the technical assistance; Drs Muhammad Yazid Jalaludin and Sarni binti Mat Junit (University of Malaya, Malaysia) for providing us the unpublished clinical information. This work was partly supported in part by JSPS KAKENHI Grant Number JP15K09630 from the Japan Society for the Promotion of Science, and a grant from the Ministry of Health, Labour and Welfare, Japan (Jitsuyoka [Nanbyo]-Ippan-014).

\section{Disclosure}

The authors have no financial relationships relevant to this article to disclose.

\section{Author contributions}

S.N. and T.H. designed the project. S.N., C.S. and K.A. conducted sequencing analyses. S.N. carried out in vitro experiments. L.A.F., K.F. and Z.F. and H.K. clinically characterized the patients and collected biological samples. K.K. conducted histological analysis. S.N. wrote the manuscript, and L.A.F edited the manuscript. 
Supplementary Table 1 In vitro functional activities of TPO mutants

\begin{tabular}{|c|c|c|c|c|c|}
\hline \multirow[b]{2}{*}{ TPO mutation } & \multicolumn{3}{|c|}{ Functional analysis } & \multicolumn{2}{|c|}{ Clinical information } \\
\hline & Cells; transfection & Assay methods & $\begin{array}{l}\text { Residual } \\
\text { activity }\end{array}$ & Clinical phenotype & The opposite allele \\
\hline Asp224del ${ }^{\mathrm{a}}$ & HEK293; stable & Amplex Red & Present & $\begin{array}{l}\text { Nonautoimmune } \\
\text { hypothyroidism }\end{array}$ & c. $820-2 A>G$ \\
\hline Asp240Asn ${ }^{\text {b }}$ & CHO-K1; transient & Guaiacol oxidation & Absent & $\begin{array}{l}\mathrm{CH} \text { (partial iodine } \\
\text { organification defect) }\end{array}$ & p.Cys808fs \\
\hline $\operatorname{Arg} 341 \mathrm{Gln}^{\mathrm{c}}$ & HEK293; transient & Amplex Red & Absent & $\mathrm{CH}$ (organification unknown) & p.Gly860Arg \\
\hline Gly387Arg $^{\mathrm{d}}$ & HEK293; stable & Amplex Red & Present & $\begin{array}{l}\text { Nonautoimmune } \\
\text { hypothyroidism }\end{array}$ & Homozygous \\
\hline Ile447Phe ${ }^{\mathrm{e}}$ & CHO-K1; transient & Guaiacol oxidation & Absent & $\begin{array}{l}\mathrm{CH} \text { (total iodine } \\
\text { organification defect) }\end{array}$ & Unknown \\
\hline Tyr453Asp ${ }^{\mathrm{e}}$ & CHO-K1; transient & Guaiacol oxidation & Absent & $\begin{array}{l}\mathrm{CH} \text { (total iodine } \\
\text { organification defect) }\end{array}$ & Homozygous \\
\hline $\operatorname{Trp} 527 \mathrm{Cys}^{\mathrm{a}}$ & HEK293; stable & Amplex Red & Present & $\begin{array}{l}\text { Nonautoimmune } \\
\text { hypothyroidism }\end{array}$ & Homozygous \\
\hline Gly553Cys $^{\mathrm{b}}$ & CHO-K1; transient & $\begin{array}{l}\text { IF and guaiacol } \\
\text { oxidation }\end{array}$ & Absent & $\begin{array}{l}\text { Nonautoimmune } \\
\text { hypothyroidism }\end{array}$ & $\begin{array}{l}\text { p.Asp574 } \\
\text { Leu575del }\end{array}$ \\
\hline Asp574_Leu575del ${ }^{b}$ & CHO-K1; transient & $\begin{array}{l}\text { IF and guaiacol } \\
\text { oxidation }\end{array}$ & Present & $\begin{array}{l}\text { Nonautoimmune } \\
\text { hypothyroidism }\end{array}$ & p.Gly553Cys \\
\hline Gly590Ser ${ }^{\mathrm{e}, \mathrm{f}}$ & CHO-K1; transient & Guaiacol oxidation & Present & $\begin{array}{l}\mathrm{CH} \text { (total iodine } \\
\text { organification defect) }\end{array}$ & Homozygous \\
\hline $\operatorname{Arg} 665 \operatorname{Trp}^{g}$ & CHO-K1; transient & Guaiacol oxidation & Absent & CH (organification unknown) & p.Gly771Arg \\
\hline Gly771 Arg ${ }^{g}$ & CHO-K1; transient & Guaiacol oxidation & Absent & $\mathrm{CH}$ (organification unknown) & p.Arg665Trp \\
\hline Glu799 Lys $^{\mathrm{e}}$ & CHO-K1; transient & Guaiacol oxidation & Absent & $\begin{array}{l}\mathrm{CH} \text { (total iodine } \\
\text { organification defect) }\end{array}$ & p.Glu17fs \\
\hline Cys $808 \mathrm{fs}^{\mathrm{e}}$ & CHO-K1; transient & Guaiacol oxidation & Absent & $\begin{array}{l}\mathrm{CH} \text { (total iodine } \\
\text { organification defect) }\end{array}$ & Homozygous \\
\hline Gly860Arg ${ }^{\mathrm{c}}$ & HEK293; transient & Amplex Red & Absent & CH (organification unknown) & p.Arg341Gln \\
\hline
\end{tabular}

Abbreviations: $\mathrm{CH}$, congenital hypothyroidism; IF, immunofluorescence.

${ }^{a}$ Present report. ${ }^{\text {b }}$ Kotani T et al., J Endocrinol 1999160 267-273. ${ }^{\text {c }}$ Narumi S et al., J Clin Endocrinol Metab 201196 E1838-1842.

${ }^{\mathrm{d}}$ Lee CC et al., Horm Res Paediatr 201481 356-360. ${ }^{\mathrm{e}}$ Bikker H et al., J Clin Endocrinol Metab 199782 649-653. ${ }^{\mathrm{f}}$ This mutation is located in the exonic splice site. ${ }^{\mathrm{g}}$ Umeki K et al., Eur J Endocrinol 2002 146 491-498. 


\begin{tabular}{|c|c|c|c|}
\hline & Classification & Phenotypes & Representative genotype \\
\hline $100 \%$ & $\begin{array}{l}\text { Mutation } \\
\text { non-carriers }\end{array}$ & $\begin{array}{l}\text { Normal TSH } \\
\text { Normal thyroid size }\end{array}$ & WT (homozygous) \\
\hline $50 \%$ & $\begin{array}{l}\text { Monoallelic } \\
\text { mutation carriers }\end{array}$ & $\begin{array}{l}\text { Normal TSH } \\
\text { Normal thyroid size }\end{array}$ & Cys808fs ; WT [1] \\
\hline $30 \%$ & Mild TPO deficiency & $\begin{array}{l}\text { Subtle elevation of } \mathrm{TSH} \\
\text { Marked goiter } \\
\text { High } \mathrm{T}_{3} \text { to } \mathrm{T}_{4} \text { molar ratio } \\
\text { High } \mathrm{Tg}\end{array}$ & $\begin{array}{l}\text { Gly387Arg; Gly387Arg[2] } \\
\text { Trp527Cys; Trp527Cys † } \\
\text { Asp224del; c.820-2A }>\text { G † } \\
\text { Gly553C; Asp574 Leu575del[3 }\end{array}$ \\
\hline $15 \%$ & Severe TPO deficiency & $\begin{array}{l}\text { Marked elevation of TSH } \\
\text { Marked goiter } \\
\text { Very high } \mathrm{KClO}_{4} \text { discharge rate } \\
\text { High } \mathrm{Tg}\end{array}$ & $\begin{array}{l}\text { Gln446His; Trp527Cys[4] } \\
\text { Cys808fs (homozygous) [1] }\end{array}$ \\
\hline
\end{tabular}

Supplementary Fig. 1 Correlation between clinical phenotypes and TPO genotypes

Mutations with residual activity are underlined. Previously, it has been known that biallelic TPO mutation carriers show the severe TPO deficiency phenotype (markedly high TSH, marked goiter, high $\mathrm{KClO}_{4}$ discharge rate and high $\mathrm{Tg}$ ), while monoallelic mutation carriers and mutation non-carriers have normal thyroid function and morphology. Here, we define a new subtype of TPO deficiency, mild TPO deficiency, which presents subtle elevation of serum TSH, marked goiter, high $\mathrm{T}_{3}$ to $\mathrm{T}_{4}$ molar ratio and high $\mathrm{Tg}$. Abbreviations: $\mathrm{Tg}$ thyroglobulin; WT, wildtype. $\dagger$ Present report

References: (1) Abramowicz MJ et al., J Clin Invest 199290 1200-1204. (2) Lee CC et al., Horm Res Paediatr 201481 356-360. (3) Kotani T et al., J Endocrinol 1999 160:267-273. (4) Simm D et al., Acta Paediatr 200998 1057-1061.

\section{References}

1. Rastogi MV, LaFranchi SH (2010) Congenital hypothyroidism. Orphanet J Rare Dis 5:17.

2. Stanbury JB, Hedge AN (1950) A study of a family of goitrous cretins. J Clin Endocrinol Metab 10:14711484.

3. Abramowicz MJ, Targovnik HM, Varela V, Cochaux P, Krawiec L, et al. (1992) Identification of a mutation in the coding sequence of the human thyroid peroxidase gene causing congenital goiter. J Clin Invest 90:12001204.

4. Ris-Stalpers C, Bikker H (2010) Genetics and phenomics of hypothyroidism and goiter due to TPO mutations. Mol Cell Endocrinol 322:38-43.

5. Bakker B, Bikker H, Vulsma T, de Randamie JS, Wiedijk BM, et al. (2000) Two decades of screening for congenital hypothyroidism in The Netherlands: TPO gene mutations in total iodide organification defects (an update). J Clin Endocrinol Metab 85:3708-3712.

6. Mortoglou A, Candiloros H (2004) The serum triiodothyronine to thyroxine (T3/T4) ratio in various thyroid disorders and after Levothyroxine replacement therapy. Hormones (Athens) 3:120-126.
7. Yoshizawa-Ogasawara A, Abe K, Ogikubo S, Narumi S, Hasegawa T, et al. (2016) Transient congenital hypothyroidism caused by compound heterozygous mutations affecting the NADPH-oxidase domain of DUOX2. J Pediatr Endocrinol Metab 29:363-371.

8. McKenna A, Hanna M, Banks E, Sivachenko A, Cibulskis K, et al. (2010) The Genome Analysis Toolkit: a MapReduce framework for analyzing next-generation DNA sequencing data. Genome Res 20:1297-1303.

9. Wang K, Li M, Hakonarson H (2010) ANNOVAR: functional annotation of genetic variants from highthroughput sequencing data. Nucleic Acids Res 38:e164.

10. Narumi S, Muroya K, Asakura Y, Aachi M, Hasegawa T (2011) Molecular basis of thyroid dyshormonogenesis: genetic screening in population-based Japanese patients. J Clin Endocrinol Metab 96:E1838-1842.

11. Lee CC, Harun F, Jalaludin MY, Heh CH, Othman R, et al. (2014) Variable clinical phenotypes in a family with homozygous c. $1159 \mathrm{G}>\mathrm{A}$ mutation in the thyroid peroxidase gene. Horm Res Paediatr 81:356-360.

12. Kotani T, Umeki K, Kawano J, Suganuma T, Hishinuma A, et al. (2003) Partial iodide organification defect 
caused by a novel mutation of the thyroid peroxidase gene in three siblings. Clin Endocrinol (Oxf) 59:198206.

13. Carpi A, Bianchi R, Zucchelli GC, Del Corso L, Levanti C, et al. (1979) Effect of endogenous thyroid stimulating hormone levels on the secretion of thyroid hormones in man. Acta Endocrinol (Copenh) 92:73-84.

14. Hishinuma A, Takamatsu J, Ohyama Y, Yokozawa T, Kanno Y, et al. (1999) Two novel cysteine substitutions (C1263R and C1995S) of thyroglobulin cause a defect in intracellular transport of thyroglobulin in patients with congenital goiter and the variant type of adenomatous goiter. J Clin Endocrinol Metab 84:1438-1444.

15. Hishinuma A, Fukata S, Kakudo K, Murata Y, Ieiri T (2005) High incidence of thyroid cancer in long-standing goiters with thyroglobulin mutations. Thyroid 15:1079-1084

16. Hishinuma A, Fukata S, Nishiyama S, Nishi Y, Oh-Ishi $\mathrm{M}$, et al. (2006) Haplotype analysis reveals founder effects of thyroglobulin gene mutations C1058R and C1977S in Japan. J Clin Endocrinol Metab 91:31003104.

17. Bikker H, Baas F, De Vijlder JJ (1997) Molecular analysis of mutated thyroid peroxidase detected in patients with total iodide organification defects. J Clin Endocrinol Metab 82:649-653.
18. Kotani T, Umeki K, Yamamoto I, Maesaka H, Tachibana $\mathrm{K}$, et al. (1999) A novel mutation in the human thyroid peroxidase gene resulting in a total iodide organification defect. J Endocrinol 160:267-273.

19. Umeki K, Kotani T, Kawano J, Suganuma T, Yamamoto I, et al. (2002) Two novel missense mutations in the thyroid peroxidase gene, R665W and G771R, result in a localization defect and cause congenital hypothyroidism. Eur J Endocrinol 146:491-498.

20. Simm D, Pfarr N, Pohlenz J, Prawitt D, Dorr HG (2009) Two novel mutations in the human thyroid peroxidase (TPO) gene: genetics and clinical findings in four children. Acta Paediatr 98:1057-1061.

21. Baryshev M, Sargsyan E, Wallin G, Lejnieks A, Furudate S, et al. (2004) Unfolded protein response is involved in the pathology of human congenital hypothyroid goiter and rat non-goitrous congenital hypothyroidism. J Mol Endocrinol 32:903-920.

22. Matsuda A, Kosugi S (1997) A homozygous missense mutation of the sodium/iodide symporter gene causing iodide transport defect. $J$ Clin Endocrinol Metab 82:3966-3971.

23. Kasahara T, Narumi S, Okasora K, Takaya R, Tamai H, et al. (2013) Delayed onset congenital hypothyroidism in a patient with DUOX2 mutations and maternal iodine excess. Am J Med Genet A 161A:214-217. 